\title{
Innovation in International Law and Global Finance: Estimating the Financial Impact of the Cape Town Convention
}

by

\author{
Anthony Saunders*, Anand Srinivasan** and Ingo Walter ${ }^{\star \star *}$
}

\begin{abstract}
This paper examines the financial impact of a transfer of legal sovereignty covering the rights to collateral to an international regime in the case of the Cape Town Convention and Protocol covering international mobile assets, specifically commercial aircraft and related equipment, which came into force in 2004. We estimate the impact on financing costs facing airlines based in signatory countries in terms of access to financial markets and interest differentials, debt rating migration and stock prices using rating-sensitivity analysis, OLS regressions and event studies. We find that the present value of the resulting financing cost reductions are very significant and are biased in favor of developing countries, the sources of much of the growth in demand for commercial aircraft going forward. The results suggest the power of changes in the legal framework of financial markets to influence the costs and pricing of global financial flows.
\end{abstract}

Keywords: Law and finance; secured lending; aircraft finance; leasing; sovereign risk; asset securitization.

JEL: K11, K33, F34, G15, G28, G33,

*Department of Finance, Stern School of Business, New York University, 44 West $4^{\text {th }}$ Street, New York, NY 10012 USA. asaunder@stern.nyu.edu.

**Department of Finance and Accounting, NUS Business School, National University of Singapore, 1 Business Link, BIZ1 Building 04-34, Singapore 117952. bizas@nus.edu.sg

${ }^{* * *}$ Department of Finance, Stern School of Business, New York University, 44 West $4^{\text {th }}$ Street, New York, NY 10012 USA. iwalter@stern.nyu.edu 


\section{Introduction}

Financial markets tend to be highly sensitive to regulatory changes. The premium they place on static and dynamic efficiency is instrumental in deciding which intermediation channels, financial instruments, risk management techniques, and financial centers are used. Small changes in the legal and regulatory overlay of the market can create dramatic shifts in financial flows. Regulation creates both benefits and costs, and the balance between the two the "net regulatory burden" [Kane, 1983, 1989] - can elicit important responses on the part of the users of capital, investors and financial intermediaries.

A number of studies have focused on the interaction between the legal infrastructure and financial markets [REFS] but few have addressed distinctly international aspects involving treaties and conventions signed and ratified by sovereign states, thereby subjecting domestic financial law and regulation to external constraints. In doing so, countries cede a certain degree of national sovereignty in return for what are presumed to be significant financial gains that accrue to market participants, the real sector of the economy, and society at large.

Once such case is the Cape Town Convention and Protocol covering international mobile assets, specifically commercial aircraft and related equipment, which came into force in 2004. An earlier paper [Saunders et al, 2001] attempted to document some of the key benefits. This paper reexamines these financial impacts using a contemporary dataset by applying sensitivity analysis to a range of capital cost savings under alternative financing structures 
as well as regression analysis and event study analysis applied to the cost of capital and share prices of the airline end-users.

\section{The Legal Background}

During the late1990s, the UN agency that deals with private law conventions, the Unification of Private Law (UNIDROIT), and the International Civil Aviation Organization (ICAO) joined to create a legal framework under which lenders and lessors with a financial interest in aircraft, aircraft engines and certain other mobile equipment would have clear title to the collateral in the event of bankruptcy or other interruption of debt service. The objective was to reduce barriers posed by the variety of approaches in local legal systems to security and title reservation rights, which either do not protect lenders in the event of default or are unpredictable - i.e., to reduce creditors' uncertainty by providing secure and readily enforceable rights in aircraft and related equipment. In this effort, they were supported by Airbus, Boeing, various national export credit agencies, and major international financial institutions.

A diplomatic conference held at Cape Town, South Africa in November 2001 resulted in the Cape Town Convention and Protocol, with the legal texts signed by 29 countries including the United Kingdom and the United States. The Convention entered into force on 1 April 2004. It established an international interest which is recognized in all contracting states, alongside an electronic international register for commercial airframes, engines and helicopters. The intent of the registry is to reduce creditor uncertainty - prospective creditors can 
be sure of the priority of their interest at the time of financing or any change in financial arrangements. Moreover, any country that has ratified the Convention and Protocol commits creditors to deregister the aircraft and procure its export, take possession or control of the aircraft, sell or grant a lease in the aircraft, and collect or receive income or profits arising from the management or use of the aircraft.

Key articles of the Convention define "international interest," criteria for an international interest to be constituted, and creation of an international registry for the registration, amendment, extension or discharge of actual and prospective international interests, assignments, acquisitions, registrable non-consensual rights and interests, and notices of national interests. The registered international interest will generally have priority over the unregistered interest even if the registered international interest was registered with actual knowledge of the unregistered interest. Once a country has ratified the Convention, withdrawal or change in the terms of ratification do not affect pre-existing protection of the Convention. The courts of a contracting state selected by the parties and the courts of contracting state of which the aircraft is situated have jurisdiction to grant orders with respect to preservation of the aircraft and its value, immobilization, interim utilization, possession, control and custody of the aircraft. ${ }^{1}$

The Cape Town Convention is accompanied by a Protocol which extends the provisions of the Convention to outright sales and specifies remedies in the event of default or insolvency. Countries have two options. One is a "hard regime" under which the administrator must give the creditor the opportunity to

\footnotetext{
${ }^{1}$ For a full set of documents, see UNIDROIT [2006].
} 
take possession of the aircraft if after a specified waiting period the insolvency administrator or debtor is unable to cure all defaults and agree to perform all future obligations. ${ }^{2}$ Under this regime, the court has no powers of intervention to stay the enforcement, and the insolvency debtor must preserve the aircraft and maintain it and its value until the creditor is given the opportunity to take possession. The alternative is a "soft regime," under which the debtor must give notice to the creditor within the waiting period whether it is able to cure all defaults and agree to perform all future obligations or whether it will give the creditor the opportunity to take possession of the aircraft. If the insolvency debtor fails to give notice, the court may permit the creditor to take possession upon such terms as the court may order. Obviously the "hard regime" is preferable to creditors, as is a short waiting period such as 60 days. $^{3}$

As part of the implementation process for the Cape Town Convention and Protocol, the Secretary General of the International Civil Aviation Authority (ICAO) issued a global tender in January 2004 for an organization to establish and operate the International Registry as required under the Treaty. Aviareto, a Dublin-based joint venture of SITA SC (a Geneva-based information technology firm specializing in the aviation sector) and the Irish Government won the tender and contracted with the ICAO to perform the registry functions on a not for profit, cost recovery basis. The Registry is the vehicle for protecting international interests under the Cape Town Convention, including identification of all parties with registered claims on airborne assets. The registry went "live" on March 1,

2 An analysis of the key provisions is contained in Goode [2004].

${ }^{3}$ For a summary, see Bird \& Bird at http://www.twobirds.com/english/publications/articles/ Cape Town Convention.cfm, 8 March 2006. 
2006, by which time the Cape Town Convention had been signed by 32

countries ${ }^{4}$ and ratified by 9 countries - the protocol had come into force three months after the eighth ratification. ${ }^{5}$

The purpose of this paper is to quantify the financial gains from this international legal initiative - savings that could accrue to the airlines based in countries that sign and ratify the Cape Town Convention and Protocol. ${ }^{6}$

\section{Demand Estimates}

Both Boeing and Airbus have projected rapid growth in new aircraft demand the over 2004-2023 period. In particular, Boeing projects a market demand for commercial aircraft of around $\$ 2$ trillion over the next two decades, with demand for around 25,000 new airframes [Boeing, 2004]. Table 1 provides the Boeing delivery projections. An increasing share of the global passenger traffic is forecast to be taken up by non-American airlines. For example, Airbus predicts that the US domestic share of world traffic will decline from $20.4 \%$ in 2002 to $13 \%$ in 2022 [Airbus, 2004]. Both forecasts predict strong growth in emerging markets, particularly in Asia and the Middle East, with the least rapid growth in the U.S.

Given these comparative air traffic growth expectations -- linked to the higher relative growth rate in the purchasing needs of non-American airlines such

\footnotetext{
${ }^{4}$ Burundi, Canada, Chile, China, Congo, Cuba, France, Germany, Ghana, Italy, Jamaica, Jordan, Kenya, Lesotho, Saudi Arabia, South Africa, Sudan, Switzerland, Tanzania, Tonga, Turkey, Ukraine and the United Kingdom.

${ }^{5}$ Ethiopia, Ireland, Malaysia, Nigeria, Oman, Pakistan, Panama, Senegal and the United States.

${ }^{6}$ We use Boeing's Current Market Outlook [2004] to obtain forecasts of demand for future aircraft deliveries between 2004 to 2023. We then use these forecasts to estimate the cost savings to airlines and countries that sign and ratify the Aircraft Protocol.
} 
as those in Asia, the Middle East, Latin American, Eastern Europe and Africa -the question of availability and cost of external finance to airlines becomes crucial. It is in the context of this rapid projected growth in new commercial aircraft purchases that the benefits of the Convention, and its potential for allowing carriers to move along the financing continuum toward improved levels of debt quality, will be evaluated.

The Convention will potentially allow emerging market airlines access to secured debt on a commercial basis as well as to international capital markets by avoiding in whole or in part the conventional country-risk premium, and will give airlines increased and lower cost access to securitized global debt markets through enhanced debt ratings. In particular, the ability of emerging market airlines to better access the secured debt markets should be a major direct benefit to these carriers, as well as to the countries in which they are based. A further, indirect source of benefit is the reduction or elimination of required sovereign debt guarantees covering airline debt in emerging market economies. This will help to make marginal carriers commercially viable and free-up scarce financial resources for use in other economic development areas in the countries concerned.

\section{Methodology for Estimating Cost Savings}

We adopt the following approach to estimating the cost savings that may accrue to each country that signs and ratifies the Cape Town Convention and the Protocol. 
First, we calculate a set of estimates for savings that would accrue, per dollar of airline debt, if signing the Convention were to have resulted in an improvement in the debt ratings of the airline involved. For example, it is possible to calculate the savings that would be likely to result if the rating of an airline's bonds were to improve from BBB to A. The results derived from this analysis can be thought of as a "what-if" scenario in the sense that, if a given airline were to see an improvement in its rating from BBB to $A$, what are its savings per dollar of external debt financing that it obtains?

The principle that underlies our methodology is as follows: Adoption of the Convention and Protocol is likely to result in an increase in the credit ratings of bonds or other forms of debt contracted by airlines in a given country. This improvement in credit ratings will tend to result in a decrease in the interest rate that those airlines would have to pay on the debt. The resulting savings will depend on (a) the size of the decrease in interest costs (or coupon payments) which in turn will impact the repayment amount during the life of the debt, (b) the structure of the debt itself, and (c) the discount rate used to determine the

present value of savings over time to the airline borrower. We specify the assumptions underlying our analysis in the next three subsections of this paper, prior to undertaking the actual estimates of potential cost savings.

\subsection{Assumptions Regarding Changes in Financing Costs}

Given the divergent nature of airlines in various countries operating in very different legal and financing environments, it is difficult to predict the extent to 
which credit ratings would improve as a result of application of the Convention, and thus the amount by which the interest cost of financing would decline. To circumvent this problem, we first analyze the effect of a rating increase of 1 notch (for example for BB- to BB) for all ratings. Thus, each airline could, at its existing rating, estimate its cost savings if its rating went up one notch due to its home country signing and ratifying the Cape Town Convention and Protocol.

In actuality, an airline may achieve a rating increase of more than one notch. To illustrate this, we also examine the impact of an improvement in ratings from $B B B$ to $A A A$ and from $C C C$ to $B B B$. In the latter case this would move the debt of the airline from "junk" or "non-investment grade" status to investment grade status.

Lastly, a key element in the potential savings attributable to the Cape Town Convention and Protocol is likely to be the difference between the interest cost of secured and unsecured debt. We therefore examine the possible impact of this change in the structure of aircraft financing. Here the aggregate savings estimates are likely to be biased upward to the extent that significant amount of aircraft financing is in the form of secured loans and leases in countries which already provide the equivalent protection to lenders and lessors (e.g., Canada and the United States) or have comparable legal protections. The net gains in such countries will tend to be much smaller that in the case of countries that do not have such protections in secured financings. 


\subsection{Assumptions Regarding Type of Aircraft Financing Debt}

We assume that the maturity of aircraft financing debt is 12 years. We examine the effect of repayment of the debt under two different repayment schedules: (i) We assume that the debt is repaid in equal annual installments over a 12 year period. (ii) We assume that the entire principal amount of the debt is repaid at maturity at the end of 12 years (a "bullet" bond or loan).

\subsection{Assumptions Regarding the Discount Rate}

Lastly, we need to find an appropriate discount rate to calculate the present value of the savings conditional on a given rating upgrade and a given debt structure. Assuming a rating upgrade, the appropriate discount rate would be the interest rate that the airline pays after the upgrade. However, to bias our estimates on the conservative side, we use the simple average of the interest rate that the airline paid before the rating upgrade and the interest rate after the presumptive upgrade in its credit rating. As such, this higher discount rate is likely to result in estimates of the present value of savings that represent the lower bound of the true cost savings.

\subsection{Alternative Ways of Calculating Potential Savings}

We utilize three different methods to calculate airline savings, given our aforementioned assumptions regarding (1) the type of debt, (2) the savings due to an increase in ratings, and (3) the discount rate enumerated in Sections 3.0.13, above. 
Method 1: Fully-amortized debt - present value of annuity savings. We assume that financing is in the form of 12-year debt that is fully amortized. Repayment occurs on an annual basis in equal annuity payments. Assume a country that signs and ratifies the Convention and its Protocol were to benefit from an increase in the credit rating of its airlines from BB- to BB+. The annuity payments for a given aircraft loan, lease or bond in the BB- category would naturally be higher than those obtained in the BB+ category due to the higher cost of BB- debt relative to BB+ debt. We then take the difference in annuity payments and discounted back to the present at a discount rate equal to the average of the two interest rates - namely, the current yield (interest rate) for a BB- bond and that for a BB+ bond -- to obtain an estimate of the present value of the savings to the airline. This present value represents one estimate of the total savings per dollar borrowed over the entire life of the debt.

Method 2: Balloon payment at maturity - present value of interest savings. We assume that the 12-year loan or bond has full (bullet) principal repayment at maturity. Consequently, the difference in interest payments on an annual basis is the savings that would accrue to a given airline as a result of moving up a notch or more in its credit rating. Thus, taking the same example cited in Method 1, the difference in interest payments for a BB- debt and a BB+ debt is discounted back at the average interest rates (yields) of a BB- debt and a BB+ debt in order to obtain the present value of the savings to the airline. This present value represents the savings in interest cost for a bullet debt issue.

Method 3: Fully amortized debt - present value of interest savings. We assume, as in Method 1, that the debt is fully amortized over 12 years with equal annuity payments. However, our estimate of savings in this third approach uses only the difference in interest payments obtained in each year. As a result, over the entire life of the loan, we calculate separately (1) that component of the annuity payment which constitutes repayment of the principal and (2) that part of the annuity that constitutes interest. We calculate the difference in the interest components of the two annuities in each year and discount this series of payment differences by the average of the two interest rates. This method focuses on the savings in interest costs achieved in each year.

Method 3 used in calculating savings is thus similar to Method 1, although it results in savings estimates that are greater than Method 1. The reason is that during the initial years of repayment of the loan, most of the annuity payment would go toward repaying the interest component. Thus, the difference in interest components of the annuity payment is likely to be higher than the difference of the annuity payments in the initial years of the loan and lower in the final years of 
the loan. Since the discounting of the initial years is lower, Method 3 would in general yield a higher present value than Method $1 .{ }^{7}$

\section{Analysis}

We obtained data from the following sources. The average values of the yield to maturity of bonds of different rating classes were obtained from Standard and Poor's and Citigroup. Each of these represented the average of month-end values for the year 2003 - see Table 2 . We use these average values as the estimate of financing costs for new issuers that undertake issues at the given rating. The rating classes used were $\mathrm{AAA}, \mathrm{AA}, \mathrm{A}, \mathrm{BBB}, \mathrm{BB}+, \mathrm{BB}, \mathrm{BB}-$ and $\mathrm{CCC}$. Issuers with a D rating have defaulted, and therefore were not considered in this study. We also obtained from the Thomson Financial Security Data Corporation New Issues Database (SDC) the yields to maturity on newly issued bonds in 2003. We focused only on bonds that are non-convertible, have no call provisions, and are not linked to equity issues or unit issues. We excluded floating rate bonds.

\footnotetext{
${ }^{7}$ To illustrate this, consider the following example: Suppose the interest rate before adoption of the Protocol was 10\% (Loan 1) and after adoption of the Protocol, the interest rate reduced to $5 \%$ (Loan 2). The constant annuity payment that would repay a loan taken at the first interest rate would be $\$ 0.1128$ per year for 12 years. The corresponding annuity payment for Loan 2 is $\$ 0.1468$. Thus, Method 1 would calculate savings as the difference in these two annuity payments $(\$ 0.034)$ for 12 years at the average of the two interest rates $(7.5 \%)$. However, the interest components of the loan in the first year are $\$ 0.10$ and $\$ 0.05$ for Loans 1 and 2 respectively. The difference in the interest components of the loan is $\$ 0.05$, which is greater than the difference of the annuity payments. As more of the principal amount is repaid, the difference in interest components would decline. In this particular example, the difference in interest payments in the last period (year 12) is $\$ 0.0079$. The total sum of difference in interest payments is the same as the sum of the difference in annuity payments. However, Method 3 results in more of the savings accruing earlier than does Method 1.
} 
We also investigated the difference in yields between secured and unsecured bonds. On average we find that the difference in average values of the yield to maturity between secured and unsecured bonds was 258 basis points (or 2.58\%). For purposes of this study, we therefore assume that the difference in financing costs between secured and unsecured bonds is 250 basis points. This assumption is likely to provide an underestimate of the actual savings attributable to a secured bond issue relative to an unsecured one, which biases our estimates to the conservative end of probable outcomes. We assume that the secured rate is 40 basis points above the AAA yield in our sample. Based on a difference of 250 basis points between the secured and unsecured yields, this implies that the unsecured yield is 290 basis points above the AAA yield.

\subsection{Estimates of Cost Savings Accruing to Individual Airlines}

Table 2 shows the results of moving along the financing continuum (credit spectrum) per $\$ 1$ (one dollar) principal of debt. This exhibit demonstrates the savings by of improving one rating, three ratings, or moving from an unsecured bond to a secured bond. Savings are calculated by three methods. In all cases, interest rates used are from Table 2. In Method 1, we assume that the loan is repaid in equal annual installments over 12 years. The benefit of going from one category to another is the present value of the different in annuity payments for

loans at each of the two interest rates. We discount this difference in annuity payments at the average of the two interest rates. In Method 2, we assume that 
the loan principal amount is repaid fully only at maturity (i.e. after 12 years). We discount the difference in interest payments of loans for a period of 12 years assuming annual repayment at an interest rate equal to the average of the two interest rates. In Method 3, we assume that the loan is repaid in equal annual installments as in Method 1. However, we find the present value of only the difference in interest payments (i.e. the difference in the part of the annuity payment that goes to repaying the interest alone, and not the principal). We discount this difference in interest payments at an average of the two interest rates. All savings are per dollar of loan amount.

We find that rating increases lead to significant savings in present value terms for all methods used and for all types of debt. Most significantly, a move from a $\mathrm{CCC}$ rating to a $\mathrm{BB}$ - rating (a move of one notch only) results in a minimum present value cost saving of $33 \%$ (or 33 cents per $\$ 1$ ) over a 12 year debt maturity horizon. While moves within the A category do not appear to result in large savings, most other rating moves result in cost savings of at least $5 \%$ or 5 cents per dollar of debt. Given the size of the capital investment required for aircraft, even small percentage savings add up to significant absolute savings in dollar terms.

\subsection{Cost Savings at the Country Level}

To calculate the benefits for each country in the aggregate, one needs additional data with regard to demand for aircraft financing. We use two approaches to estimate this demand. 
First, we calculate the total number of aircraft departures worldwide using the World Development Indicators 2003. For each country, we then use the percentage of departures in that country relative to the worldwide total as our first estimate of the fraction of the total worldwide demand for aircraft attributable to a given country. We multiply this fraction by the total [Boeing, 2004] predicted demand for aircraft over the 20 years to obtain the dollar estimate of demand for aircraft in the given country. The overall amount is estimated at $\$ 2$ trillion in total in 2003 dollars. This estimate of future demand will be henceforth referred to as the "Aircraft Departures Forecast."

Our second set of estimates for aircraft demand comes directly from Boeing [2004], henceforth referred to as the "Boeing Forecast." The disadvantage of this second set of estimates is that it provides forecasts for only 74 countries. The first approach provides estimates for 149 countries. The advantage of the Boeing estimates is that these are likely to be much more precise, since the information used by Boeing in its forecasts is likely to be much more comprehensive and granular, taking into account future macro-economic and political conditions as well as other proprietary market research.

Having obtained aggregate dollar demand for future aircraft using one of the two approached described above, we estimate savings that would accrue to the given country if it acceded Cape Town Convention and Protocol using three different methods.

We can use one of the two estimates of future aircraft demand in dollars and multiply it by the potential total dollar savings for the different sets of rating 
increases attributable to the legal initiative. This provides an estimate of the potential savings in financing costs at the country level. Recall that one can estimate savings per dollar in three ways, and there are several possible increases in rating categories.

We present results in the aggregate level - for the world as a whole and for countries into World Bank designated income groups. are (i) High Income, (ii) Low Income, (iii) Lower Middle Income and (iv) Upper Middle Income. We present results both for the total savings that would accrue to all countries in each group as a whole as well as average savings that may be expected per country. ${ }^{8}$ In Table 1a, we examine the impact going from an unsecured bond rating to a secured bond rating using the World Development Indictor (WDI) estimate of aircraft demand, and savings using various possible rating moves.

It is important to point out that the savings per country that are calculated in these tables assume that all airlines in the given country go from a given rating to another rating. They do not depend on any improvement in the sovereign rating. For example, the minimum savings over 20 years for China amount to a present-value $\$ 76$ billion on a total predicted demand of $\$ 183$ billion over the 2004-2023 period using the Boeing forecast. This cost calculation assumes that all airlines in China go from a CCC rating to a BBB rating as a consequence of China's benefiting from the Cape Town Convention and Protocol. Clearly, this assumption may not be valid for all airlines in China - some may have a rating of CCC, others may already have a BBB rating. We find that a move of all airlines in

\footnotetext{
${ }^{8}$ These total savings assume that each country in the given group signs the Aircraft Protocol.
} 
China from CCC to BB- would result in a minimum combined savings of $\$ 60$ billion.

\subsubsection{Direct Cost Savings Using Country-level Lending Rates}

The previous section discussed the impact of savings that would accrue to a given country's airlines based on different sets of rating increases for airlines in the given country. However, the interest rates upon which these were based are US corporate bond rates for each of the rating categories. Currently, these are not likely to be the borrowing rates available to airlines in many emerging market countries, since many do not have access to US or European bond markets or the offshore Eurobond market. Consequently, the appropriate benchmark rates in this case would be the domestic lending (loan) rates in each of these countries.

In particular, we assume that the cost of borrowing for an airline in a given country is the domestic lending rate of that country as stated in the World Bank's Development Indicators ${ }^{9}$ This is a reasonable assumption, especially for developing countries, since airlines in these countries are unlikely to have access to international financing due to inadequate legal protections of creditors. Once a given country signs and ratifies the Cape Town Convention and Protocol, however, external financing is likely to be available, and therefore international financing rates (both loans and bonds) would become available to airlines in these markets.

\footnotetext{
${ }^{9}$ Caution should be used in interpreting these results. In particular, the lending rates in several emerging markets are not market determined lending rates, but rather government controlled rates.
} 
International lending contracts frequently price interest rates above some benchmark rate. One frequently used benchmark rate is the London Interbank Offered Rate (LIBOR). Even loans that are not explicitly benchmarked to this interest rates are, in fact, implicitly linked to this rates since it represents the interest rate available to the most creditworthy borrowers.

We assume that an airline that issues debt protected by the Convention's Protocol would secure a loan at an interest rate equal to the 365 day LIBOR rate plus $40 \mathrm{bp}$. For purposes of our calculations, we use the underlying average month-end LIBOR rates for year 2003. These data were obtained from the Datastream database. ${ }^{10}$ Specifically, we compare savings if the loan were obtained at LIBOR +40 basis points -- the loan rate for secured international borrower -- relative to the domestic lending rate in the given country in 2003, using the three methods of savings enumerated in earlier sections of this paper.

The results of these secured loans cost savings (e.g., domestic loan rate minus LIBOR $+40 \mathrm{bp}$ ) attributable to secured loans are shown in aggregate in Table 4, under the four designated World Bank Income Groups.

\footnotetext{
${ }^{10}$ In the earlier section and in exhibit 1 , we had assumed a secured lending rate of AAA yield + 40 basis points, i.e., we assumed that the benchmark rate was the AAA yield and secured loan had a spread of 40 basis points over AAA. The analysis in that section and exhibit 2 was more in the spirit of a "what-if" analysis scenario analysis. Here, we try to get closer the actual data to find which benchmark rates are actually used for secured debt issues. Upon examination of data from the SDC database of secured debt issues, we found that all debt issues where a benchmark rate was explicitly specified used either the 1-month LIBOR rate or the 3-month LIBOR rate as the benchmark rate. By using the 365-day LIBOR interest rate (which will be higher than the 1 month and 3 month interest rate due to the term premium), we obtain an estimate of savings lower than what it would be if the actual benchmark LIBOR rates were used. This estimate of secured debt financing interest rate is a more realistic approximation than that used earlier.
} 


\subsubsection{Direct Cost Saving Attributable to Secured Borrowing}

The calculations summarized in Table 4 contain a large number of possible results for different rating, security and model scenarios. Different scenarios will be of interest to different countries and airlines. Table 5 shows the mean country and total cost savings, in millions of 2003 dollars, for countries in each World Bank designated income group in going from unsecured to secured borrowing.

In terms of aggregate present value Worldwide savings over 20 years Method 1 shows $\$ 267$ billion in cost savings while Methods 2 and 3 show $\$ 299$ billion and $\$ 290$ billion respectively. Since the Boeing forecast suggests a 20 year demand for aircraft in 2003 of $\$ 2$ trillion, this represents total cost savings of between $10 \%$ and $15 \%$ due to the Protocol in terms of new aircraft financing. It can be argued that some high-income countries such as the US and Canada already have protection for secured creditors comparable to that envisaged by the Cape Town Convention and Protocol. If one were to exclude the US, UK and Canada from the calculation of aggregate savings, we obtain aggregate savings of $\$ 149$ billion and $\$ 223$ billion. Thus, exclusion of such countries still results in materially large estimates for gains to countries on aggregate. There are also significant savings for low income countries of between $\$ 8$ to $\$ 12$ billion, depending on which of the three cost savings methods of estimation are used. Indeed on average low-income countries would save between $\$ 216$ million and \$322 million. See Table 5. 
While the mean of the aggregate savings for countries migrating from a BBB rating to AAA is $\$ 1.2$ billion, for individual countries such as China the savings would be much higher. Based on the estimated value of future deliveries over 20 years of $\$ 91$ billion, China would be estimated to save between $\$ 8$ billion and $\$ 12$ billion in financing costs, depending on which of the three methods is used. ${ }^{11}$ Based on the Boeing aircraft delivery estimate of $\$ 183$ billion and the applicable interest rate, the savings are estimated to be between $\$ 38$ billion and $\$ 62$ billion.

Similarly, India is estimated to save between $\$ 10.4$ billion and $\$ 15.7$ billion based on a Boeing estimate of future demand of $\$ 20$ billion. Thus, the present value savings are estimated to be over $50 \%$ of the actual principal amount needed to purchase aircraft. For Brazil, the savings amount also exceeds the principal amount of the aircraft financings - on a Boeing-estimated demand of $\$ 32.5$ billion, Brazil can expect to save between $\$ 53$ billion and $\$ 59$ billion.

The aggregate global cost savings range between $\$ 494$ billion to $\$ 729$ billion or approximately $15 \%$ to $20 \%$ of the expected cost of the future (20 year) demand for airline deliveries (in 2003 dollars). If we exclude the US, UK and Canada from these estimates, we obtain estimates for aggregate savings to lie between $\$ 371$ billion to $\$ 524$ billion. As can be seen from these examples, the expected cost savings over 20 years - even for lower income countries - as a result of the adoption of Cape Town Convention and Protocol are likely to be very material indeed.

\footnotetext{
${ }^{11}$ Standard \& Poors assigns a sovereign debt rating of BBB to China in 2003. Thus, the cost saving here is probably close to the actual savings to China.
} 


\subsubsection{Cost Savings Based on Sovereign Rating}

Finally, we compute another set of estimates on a country-by-country basis for all countries where a sovereign debt rating was assigned by Standard and Poor's in 2004. For each of these countries, we compute present-value savings using both the Boeing estimate of aircraft demand and the aircraft departures forecast. For countries where the Boeing forecast was available, we present results for this forecast. For countries where the Boeing forecast was not available, we estimate cost savings using the aircraft departures forecast. Most airlines in a country will typically have ratings that are lower than or equal to the sovereign rating of a given country. For example, in the United States (sovereign rating of $A A A$ ), only one airline company had a debt rating of AAA and only 18 corporations in total had a rating of AAA. ${ }^{12}$

This approach to estimating cost savings can be illustrated using Turkey as an example. Turkey has an aircraft demand of $\$ 20$ billion using the Boeing 20 year forecast, and had a sovereign rating of B in 2003 assigned by S\&P. Given that the rating increases in our sample do not have a sovereign debt rating of $B$, we assume that the corporate rating of BB- corresponds to a sovereign rating of B. ${ }^{13}$ Companies in Turkey would tend to have ratings that are lower than BBwhen accessing international financing markets. This implies that they should have rating of $\mathrm{CCC}$ or below. For Turkey, the minimum savings would then be

\footnotetext{
${ }^{12}$ This was found using the rating of long term debt in 2003 of the given companies from the Standard and Poor's Compustat database which provides information of financial statements of companies operating in the U.S.

${ }^{13}$ This would result in an underestimate of savings as the rating of $B$ is actually lower than the BB- rating.
} 
about $\$ 6.6$ billion if its airlines achieved even a single notch increase in rating on account of signing the Protocol.

\subsection{Impact on Ratings}

In this section, we analyze the impact of signing the Protocol on the sovereign rating of the country that signs the Protocol. We also analyze the likelihood of a rating increase on account of a change in the debt structure from unsecured to secured from the perspective of airline companies. Lastly, we analyze the impact of an increase in rating on the overall interest cost of the company, even if the debt is not covered by the Protocol.

Rating agencies use numerous operating and financial measures for an issuer before assigning a rating to the given company. The goal is to find what effect a reduction in interest rates due to the signing of the Protocol would have on an airline's credit rating.

Here we use the Standard and Poor's Compustat database to obtain information on the rating on the long term debt of a given airline as well as financial information required to compute the four accounting variables -- profit margin (defined as EBITDA to sales), total assets, leverage and interest rate (defined as the interest expense to book value of long term debt) in $2003 .{ }^{14}$ Given that our earlier analysis focused only on companies that have a rating of

\footnotetext{
${ }^{14}$ The rating in the database is the rating of the given company given by S\&P itself. While the Compustat database covers most public companies listed in the U.S, ratings are not available for all companies.
} 
$\mathrm{CCC}$ or higher, we present results for ratings from $\mathrm{AAA}$ to $\mathrm{CCC} .{ }^{15}$ Out of the total of 1,873 airlines, only 18 have a rating of AAA. Thus, despite the AAA sovereign rating of the US, a majority of the American companies have ratings significantly lower. In this sample, BBB is the most common rating for airlines.

The benchmark reduction in interest rate that we will consider is 250 basis points. Recall from our earlier analysis that secured interest rate was lower than the unsecured interest rate by $2.58 \%$ (or 258 basis points). If a given airline were to retire all of its existing debt and reissue that debt as secured debt, which would result in an overall reduction in its interest cost of about $2.5 \%$. Would this result in an increase in rating? If so, how much would this increase be?

In general, companies with a higher rating tend to pay a significantly lower interest rate on debt, have lower leverage, exhibit higher profit margins and are larger as measured by total assets. We can identify what would happen if the interest rate on a company's entire debt experienced a reduction of 250 basis points. Suppose an airline with a CCC rating was paying a median interest rate of $10.67 \%$. If that airline experienced a reduction of 250 basis points, its interest rate would fall to $8.17 \%$. As a comparison, the typical company with one higher rating of $\mathrm{B}$ had a median interest rate of $8.73 \%$. Thus, reduction of this interest rate would make this airline more similar to peer companies in the B category. Similarly, the median interest rate paid by a BBB company was $5.99 \%$. A decrease of 250 basis points in its interest cost would result in an average

\footnotetext{
${ }^{15}$ We winsorize all variables at the $1^{\text {st }}$ and $99^{\text {th }}$ percentile to minimize the impact of outliers on our analysis.
} 
interest cost of $3.49 \%$. As a comparison, AAA companies had an average interest cost of $3.54 \%$.

It is important to recognize in this analysis that the interest rate is determined by several factors such as the risk of an airline's operations, its leverage, the state of the economy in which the airline operates, and so on. The signing of the Cape Town Convention and Protocol (and the existence of the Registry) would result in a reduction of the risk to airline bondholders in the event of bankruptcy. This would likely lower the interest rate due to a reduction in the time it would take to repossess the aircraft in the event of bankruptcy. However, the rating of the company is also determined by several factors that are common to those that determine the interest rate such as leverage, risk and so on. Therefore, we cannot definitively conclude that a lower interest cost in isolation, without any other improvements in performance, would result in a higher rating the reason being that companies with higher ratings also tend to have lower leverage and better profit margins. However, the large magnitude of interest cost difference between secured and unsecured debt would create conditions that could result in an increase in rating of at least one notch and quite likely an increase of more than one notch as well.

\subsection{Rating Increases and Overall Interest Costs}

Here we extend this analysis by examining the impact of a rating change

on the overall interest cost of an airline. The goal is to assess the impact of a rating change that would likely occur on account of an airline issuing debt under 
the Cape Town Convention and Protocol on the interest payments it pays on its entire debt. We use the Standard and Poor's Compustat database to obtain financial and rating information on companies. Our methodology involves using the interest rate (defined as the ratio of interest expense to book value of long term debt) as the dependent variable and examining the impact of a change in rating on this interest rate. One observation consists of the interest rate paid by a given airline in a given year.

Since rating changes are relatively infrequent events, we examine all companies that had a rating available in the 5 years from 1999 to 2003. A rating increase of 1 notch is coded as +1 for the rating increase independent variable. Rating increase of 2 notches will be coded as +2 . Similarly, a rating decrease of 1 notch is coded as -1 . If a company has no rating change from the previous year, the rating increase variable is takes a value of 0 . We use ordinary least squares (OLS) regression to explain the interest rate paid by a given company. Our model is of the following form.

Interest Rate $=F$ (Increase in Rating from previous year, Control Variables)

Based on the foregoing analysis, we include the following control variables that are likely to be relevant in the determination of the interest rate: profit margin, leverage, and company size as measured by log of its total assets. In addition, we include dummy variables for each rating and the year of measurement. We also include dummy variables for the year of measurement to account for yearspecific movements in interest rate. 
Table 6 displays the results of this regression. We conduct analysis that examines the impact of an increase in rating for all companies as well as subsets of companies in different rating subsets. For the overall sample, we find that an increase in a rating of 1 notch leads to a reduction in the overall interest rate paid by the company of about $0.51 \%$. This magnitude of reduction in interest rates is significant for several sub-samples as well.

\subsection{Impact on Sovereign Rating and Indirect Benefits}

Many airlines in developing countries are either state-owned or companies where the state has a controlling ownership stake. Often, the governments in developing countries guarantee the debt of certain state-owned enterprises. To the extent that signing and ratification the Cape Town Convention and Protocol allows these carriers to independently raise capital, it is likely that the sovereign ratings of the country may also improve. However, to compute this possible increase in sovereign ratings, one would need detailed information on the level of state guarantees - which is not available in our dataset. Thus, the savings

estimates that we present above are exclusively savings that would accrue to airlines operating in these countries. The potential reduction in sovereign guarantees would likely result in positive spillover effects in terms of reduction of the cost of capital to the rest of the economy. However, it is not possible to gauge the magnitude of this effect with the current dataset.

Taking the example of China once again, we find that it had a sovereign rating of BBB in 2004. Thus, airlines domiciled in China would have a rating of at 
most BBB. Even if these airlines increased their ratings by 1 notch (i.e. from BBB to A), the minimum savings that would accrue to China would be $\$ 13.3$ billion. The actual savings would of course depend on the distribution of ratings among Chinese airlines and the magnitude of rating increases that may accrue to each individual airline as a result of China's signing and ratifying the Convention and benefiting from the Cape Town Convention and Protocol.

\subsection{Effects on Airline Share Prices}

All of the foregoing analysis is based on assumptions regarding the structure of savings attributable to the Cape Town Convention and Protocol and then derive the magnitude of savings under various assumptions. An alternative method of analyzing the effect of policy changes such as these - without making any assumption about the structure of savings that would accrue from them - is the "event study" methodology, a widely used technique in empirical corporate finance to evaluate the impact of an event using stock price data. Under some plausible assumptions, one can isolate the effect of an event - in this case the signing and ratification of the Cape Town Convention and Protocol - on the return on a stock (airline stocks in this instance) over and above some benchmark market index return (the so called "abnormal" or "excess" return).

A problem with using event study methodology in this context is that the methodology is well suited for events that are not anticipated and have a short duration (approximately 1-2 days). As the duration increases, or if the event is partially anticipated, the power of this method to detect the true abnormal effect 
of the event decreases - i.e., the event study method would not detect any effect even though the true effect may be significant. ${ }^{16}$ Indeed, the signing and the ratification of the Cape Town Convention and Protocol was a fairly long process. The following timeline illustrates its signing and ratification in the United States.

- May 9, 2003 - US signs Cape Town convention Aircraft Protocol

- Nov 5, 2003 - US president urges senate to approve Aircraft Protocol.

- July 22, 2004 - US senate approves treaty

- Aug 9, 2004 - US president signs treaty

- Oct 28, 2004 - US ratifies treaty

It is evident from the above that the event of the US ratifying the treaty would have been partially anticipated well before the actual date of ratification. Therefore, instead of using the conventional two-day event window, we use a 30 day window around the event date (15 days before and 15 days after ratification). ${ }^{17}$ This results in a total of 23 days trading days where airline stock price data are available.

Press coverage around the ratification date suggests that several other signatory countries were expected to sign the Convention once the US acceded to it. Given that the US ratification was the main event that several other countries were awaiting, we use this (ratification) date as the event date to compute the effect of the signing and ratification on stockholders of airline companies.

\footnotetext{
${ }^{16}$ See Thompson[19950.

${ }^{17}$ Use of longer event window has been done in the cases where the event is partially anticipated in Dahiya et al [ 2003].
} 
We examine the "abnormal return" or "excess return" on various airline stock indices available in the Datastream database. We choose those countries that had signed the Cape Town Convention and Protocol and had an airline index available. ${ }^{18}$ Out of the list of signatory countries to date, we were able to obtain airline stock index data for the following countries - Canada, Chile, China, France, Germany, Hong Kong, Italy, South Africa, Turkey, United Kingdom and United States. In addition, we were able to obtain a world airline stock price index as well as an emerging markets airline stock price index.

We compute the effect of the US ratification by two methods. First, we compute the excess return of the given airline index over the market index in the given country. ${ }^{19}$ For the world and emerging markets airline index, we use the US total market return as the benchmark return index. Our results suggest that there are significant benefits to signing the Protocol.

Table 7 summarizes these results. It shows that the world airline index had a cumulative abnormal return of $9.58 \%$ over the 30 day event window around the US ratification. This return is statistically different from zero and is also economically significant. Most other countries tend to have positive abnormal returns as well, although only the returns from China and South Africa are statistically significant with cumulative returns of $9.48 \%$ and $13.21 \%$

\footnotetext{
${ }^{18}$ Where available, we use the Dow Jones Airline index of the given country. Where the Dow Jones index is not available, we use the Datastream airlines and ports index.

${ }^{19}$ All returns are in US dollar terms.
} 
respectively. ${ }^{20}$ Using an alternative "event study" methodology, we find evidence of significant wealth gains for airline shareholders around the date then the US ratified the Cape Town Convention and Protocol. The gains computed here are completely independent of the methodology adopted in earlier sections. This suggests that the reduction in cost of debt attributable to the ratification resulted in a value gain to airline equity holders of at least $10 \%$.

\section{Summary and Conclusions}

We estimate that the adoption of the Cape Town Convention and Protocol would result in several types of savings for airlines and potentially for governments.

First, countries that sign and ratify the Cape Town Convention and Protocol would give their airlines access to capital at more competitive international financing rates. This access would lead to major reductions in financing costs, especially for airlines in developing countries which would benefit from reduced sovereign risk in addition to reduced credit risk facing lenders and investors. Using the domestic benchmark interest rate as the lending rate in a given country

\footnotetext{
20 The method above assumes that the return of the airline index on the market had a $\beta$ or market sensitivity of 1 . We relax this assumption in the next set of regressions where we regress the return on the airline indices on the market return over a period starting 365 days before the event date and ending 15 days after the event date. This results in a total of 273 days of trading data. This method allows for potentially varying dependence of the return of the airline index on the benchmark return index. Table $14 \mathrm{~b}$ shows the results of this analysis. We find that airline indices in the world as a whole, the United States, Germany and South Africa showed significant economic effects of ratification of the treaty by the United States. Germany had a coefficient estimate of 0.5094 . The interpretation of this coefficient is that there was an abnormal daily return of $0.5094 \%$ or $11.71 \%$ over the 23 trading day event period. Similarly, South Africa had a coefficient estimate of 0.5848 that corresponds to a cumulative abnormal return of $13.45 \%$. For the world as a whole, the regression coefficient of 0.5590 implies a cumulative abnormal return of $12.85 \%$. These estimates are fairly close to those obtained above.
} 
and the London Interbank Offered Rate (LIBOR) as the international benchmark rate, we find that the average country in the data sample would save, in aggregate, between $\$ 7.6$ billion and $\$ 11.1$ billion over the 20 -year estimation period, and that the average low-income country would save between $\$ 4.6$ and $\$ 6.8$ billion, based on Boeing's forecast for future aircraft orders between 2004 and 2023. Low-income countries stand to gain the most by access to international financing rates, followed by lower middle-income countries and upper middle-income countries. These are joint gains, which accrue to the airlines in the form of lower-cost of capital and to their home countries in the form of lower-cost external debt.

Second, the Cape Town Convention and Protocol (and the Registry) will provide enhanced ability for airlines (especially in developing countries) to take advantage of lower secured financing rates. We estimate that the difference in the secured and unsecured interest rate is approximately $2.5 \%$ (or 250 basis points). We estimate that this difference would lead to interest savings of between $13 \%$ and $20 \%$ per dollar of principal borrowed for aircraft financings that are not already covered by protections comparable to those provided by the Cape Town Convention and Protocol.

Third, the Cape Town Convention and Protocol will likely result in a reduction in sovereign guarantees required for airline financing and a consequent improvement in overall sovereign debt ratings. This is a collateral gain for governments not included in the direct benefits. As the relatively large financial guarantees normally required for these types of purchases are no longer 
applicable for ratifying countries, the consequent improvement in government balance sheets should improve their overall credit rating and free up scarce capital for other uses.

Fourth, signing and ratifying the Cape Town Convention and Protocol will also likely result in credit rating improvements for airlines. An increase in airline credit ratings would lead to further reductions in the interest costs for the affected carriers as a whole, extending to debt not covered directly by the Protocol. Thus, the Cape Town Convention and Protocol results in two benefits to airlines - a direct benefit in terms of reduction of interest costs for aircraft financed by secured lending subject to the terms of the Protocol, and an indirect benefit in terms of a better overall rating for all debt issued by the airline concerned. We find that a rating increase leads to a reduction of at least $0.5 \%$ in interest cost on the overall debt of an airline company based on a regression analysts that yielded statistically significant results.

Fifth, signing and ratifying the Cape Town Convention and harvesting the benefits of the Protocol will likely increase the stock market valuation of publiclytraded airlines by at least $10 \%$. This estimate is based on an "event study" of the reaction of the stock market to the US signature and ratification process during 2003 and 2004.

Although we have limited our study to the economic benefits available for the future purchase of aircraft, there are additional benefits for the purchase of engines and helicopters. In particular, this Registry will be the first and only registry available to record the financial interests in aircraft engines, so the 
economic benefits available to aircraft will also likely extend to the purchase and financing of engines. In particular, it is likely to give airlines a range of more flexible financing arrangements, since these assets are even more mobile than the aircraft themselves and have to be changed frequently for operational reasons.

\section{References}

Airbus, The Airbus Market Outlook for 2004-2023 (Toulouse: Airbus, February).

Boeing Company, Current Market Outlook 2004 (Chicago, The Boeing Company, February).

Dahiya, Sandeep, Anthony Saunders and Anand Srinivasan "Financial Distress and Bank Lending Relationships." 2003. Journal of Finance, Vol. 58. No. 1, 375399.

Goode, Roy 2004. "The Cape Town Convention on International Interests in Mobile Equipment: A Driving Force for International Asset-Based Financing." At http://www.unidroit.org/english/publications/review/articles/2002-1.pdf

Kane, Edward J. 1983. "Policy Implications of Structural Changes in Financial Markets," American Economic Review (Papers and Proceedings), 73 (May), 96-100.

Kane, Edward J. 1989. "Changing Incentives Facing Financial-Services Regulators," Journal of Financial-Services Research, 2 (September), pp. 263-272.

Saunders, Anthony, Anand Srinivasan, Ingo Walter and Jeffrey Wool. 2001. "Proposed Unidroit Convention on International Interests in Mobile Equipment," University of Pennsylvania Journal of International Economic Law (Fall).

Thompson, Rex. 1995. "Empirical methods of event studies in Corporate Finance," in Handbook in Operations Research and Management Science, Volume 9 Finance, R.A. Jarrow, V. Maksimovic and W.T Ziemba (eds), Amsterdam: Elsevier.

UNIDROIT (2006) at http://www.unidroit.org/english/conventions/mobileequipment/main.htm 
Table 1

Global Commercial Aircraft Demand Vectors 2004-2023*

\begin{tabular}{||l|l|}
\hline Worldwide demand for commercial airplanes & $\mathbf{2 5 0 0 0}$ units \\
\hline Worldwide demand for commercial airplanes in 2003 dollars & $\mathbf{\$ 2}$ trillion \\
\hline World Economic growth per year & $3.0 \%$ \\
\hline Passenger traffic growth per year & $5.2 \%$ \\
\hline Cargo traffic growth per year & $\mathbf{6 . 2 \%}$ \\
\hline
\end{tabular}

* Based on Boeing Current Market Outlook, 2004.

Table 2

Interest Rates Used to Calculate Savings

This exhibit demonstrates yields used in this study. All variables are average values based on monthly closing values for year 2003 . The values for yields of different rating bonds were obtained from Salomon yield book and Standard and Poor's. The $\mathbf{3 6 5}$ days LIBOR rate and the inflation value for U.K were obtained from World Development Indicators 2003. The secured interest rate was assumed to be $\mathbf{4 0}$ basis points over the AAA yield. The unsecured interest rate was assumed to be 250 basis points above the secured interest rate.

$\begin{array}{ll}\text { AAA yield } & 5.24 \% \\ \text { AA yield } & 5.33 \% \\ \text { A yield } & 5.59 \% \\ \text { BBB yield } & 6.93 \% \\ \text { BB+ yield } & 8.26 \% \\ \text { BB yield } & 8.57 \% \\ \text { BB- yield } & 8.62 \% \\ \text { CCC yield } & 15.81 \% \\ \text { Secured yield } & 5.64 \% \\ \text { Unsecured yield } & 8.14 \% \\ \text { 365 day US\$ LIBOR rate } & 1.37 \%\end{array}$


Exhibit 2

Saving per Dollar of Principal Amount Borrowed Due to Rating

Increase

Method 1

Benefit of going from AA to AAA

Benefit of going from $A$ to $A A$

Benefit of going from $B B B$ to $A$

Benefit of going from $\mathrm{BB}+$ to $\mathrm{BBB}$

Benefit of going from $B B$ to $B B+$

Benefit of going from $\mathrm{BB}$ - to $\mathrm{BB}$

Benefit of going from $\mathrm{CCC}$ to $\mathrm{BB}$ -

Benefit of going from $C C C$ to $B B B$

Benefit of going from Unsecured to Secured

Method 2

Benefit of going from AA to AAA

Benefit of going from $A$ to $A A$

Benefit of going from $B B B$ to $A$

Benefit of going from $\mathrm{BB}+$ to $\mathrm{BBB}$

Benefit of going from $\mathrm{BB}$ to $\mathrm{BB}+$

Benefit of going from $B B-$ to $B B$

Benefit of going from $\mathrm{CCC}$ to BB-

Benefit of going from $C C C$ to $B B B$

Benefit of going from $B B B$ to $A A A$

Benefit of going from Unsecured to Secured

$\$ \quad 0.0145$

$\$ \quad 0.0729$

Method 3

Benefit of going from AA to AAA

Benefit of going from $A$ to $A A$

Benefit of going from $B B B$ to $A$

Benefit of going from $\mathrm{BB}+$ to $\mathrm{BBB}$

Benefit of going from $\mathrm{BB}$ to $\mathrm{BB}+$

Benefit of going from $B B-$ to $B B$

Benefit of going from $\mathrm{CCC}$ to $\mathrm{BB}$ -

Benefit of going from $C C C$ to $B B B$

Benefit of going from $B B B$ to $A A A$

Benefit of going from Unsecured to Secured

$\begin{array}{ll}\$ & 0.0079 \\ \$ & 0.0225 \\ \$ & 0.1108 \\ \$ & 0.1024 \\ \$ & 0.0229 \\ \$ & 0.0037 \\ \$ & 0.4410 \\ \$ & 0.5665 \\ \$ & 0.1410 \\ \$ & 0.1997 \\ & \\ & \\ \$ & 0.0054 \\ \$ & 0.0156 \\ \$ & 0.0789 \\ \$ & 0.0761 \\ \$ & 0.0174 \\ \$ & 0.0028 \\ \$ & 0.3679 \\ \$ & 0.4638 \\ \$ & 0.0998 \\ \$ & 0.1452\end{array}$

Table 4

Benefits Based on Access to International Financing

(present-value, per World Bank country designations based on aircraft departures)

Income group

High Income Countries

Low Income Countries

Lower Middle Income Countries

Upper Middle Income Countries
Range of savings per

dollar of principal borrowed

$15 \%-25 \%$

$55 \%-82 \%$

$45 \%-62 \%$

$36 \%-56 \%$
Range of savings per

country in $\$$ billion

\$ 8.8- \$14.4

\$ 4.6- \$ 6.8

\$10.2- $\$ 14.3$

$\$ 2.9-\$ 4.4$

$>$ Mean savings per country in sample, 2004-2023

\$7.6-11.1 billion.

$>$ Mean savings per low-income country in sample, 2004-2023 \$4.6-6.8 billion.

$>$ Estimates based on 2003 domestic benchmark lending rates for countries in sample vs. LIBOR+40bp as the benchmark international lending rate.

Note: These are joint gains accruing to the airlines (cost of capital) and their home countries (cost of external debt). 
Table 5

Benefits Based on Access to Secured Financing

(present-value, per World Bank country designations using Boeing forecasts)

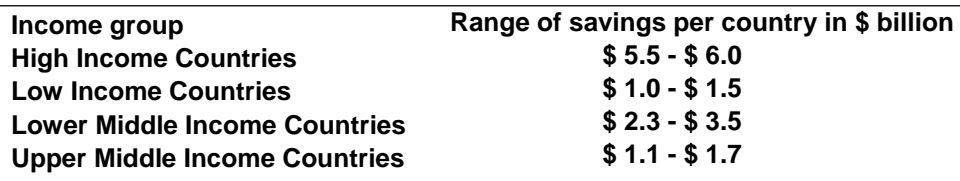

Interest cost savings estimated at between $13 \%$ and $20 \%$ of principal borrowed for aircraft financings not already covered by protections comparable to the Cape Town Convention and Protocol.

Note: These are joint gains accruing to the airlines (cost of capital) and their home countries (cost of external debt).

Improvement in Airline Credit Ratings (results of regression analysis)

\begin{tabular}{llllll} 
& Median & Median & & $\begin{array}{l}\text { Median Total } \\
\text { Assets }\end{array}$ & \multicolumn{2}{l}{$\begin{array}{l}\text { Median Profit } \\
\text { Leverage }\end{array}$} & $\begin{array}{l}\text { Number of } \\
\text { Interest Rate }\end{array}$ (in \$ million) & Margin & (bservations \\
AAA & $7.08 \%$ & $3.54 \%$ & 93083 & $25.04 \%$ & 18 \\
AA & $12.98 \%$ & $3.52 \%$ & 32696 & $23.51 \%$ & 73 \\
A & $19.12 \%$ & $5.22 \%$ & 11475 & $22.52 \%$ & 378 \\
BBB & $24.81 \%$ & $5.99 \%$ & 4977 & $18.78 \%$ & 583 \\
BB & $34.20 \%$ & $7.55 \%$ & 1615 & $13.86 \%$ & 426 \\
B & $50.27 \%$ & $8.73 \%$ & 742 & $14.70 \%$ & 337 \\
CCC & $62.64 \%$ & $10.67 \%$ & 495 & $10.56 \%$ & 58
\end{tabular}

\begin{tabular}{llllll}
\multicolumn{5}{c}{ Regression Analysis: Impact of Rating Change on Interest Cost } \\
& Profit & & Log of & Increase in & No. of \\
Intercept & Margin & Leverage & Assets & rating & observations \\
15.4578 & -0.0079 & -0.0084 & -0.5588 & $-\mathbf{0 . 5 1 1 4}$ & 8912 \\
$(0.308)^{\star * *}$ & $(0.002)^{\star \star *}$ & $(0.002)^{\star \star *}$ & $(0.026)^{\star \star *}$ & $(0.083)^{\star \star *}$ &
\end{tabular}


Table 7

Impact on Airline Stock Prices

(results of event study analysis )

\begin{tabular}{|c|c|c|c|c|c|}
\hline \multicolumn{6}{|c|}{ Univariate Analysis } \\
\hline Country & $\begin{array}{l}\text { Number of } \\
\text { observations }\end{array}$ & $\begin{array}{l}\text { Mean daily } \\
\text { excess } \\
\text { return over } \\
\text { event period }\end{array}$ & $\begin{array}{l}\text { Cumulative } \\
\text { excess } \\
\text { return over } \\
\text { event period }\end{array}$ & $\begin{array}{l}\text { Standard } \\
\text { Deviation } \\
\text { of Mean }\end{array}$ & $\begin{array}{l}t \text { statistic to test } \\
\text { if mean } \\
\text { significantly } \\
\text { different from } 0\end{array}$ \\
\hline World & 23 & $0.42 \%$ & $9.58 \%$ & $0.23 \%$ & 1.78 \\
\hline Emerging Markets & 23 & $0.11 \%$ & $2.50 \%$ & $0.24 \%$ & 0.45 \\
\hline
\end{tabular}

Regression Analysis: Effect of U.S. Ratification

$\begin{array}{llllc} & \begin{array}{l}\text { Coefficient on } \\ \text { Overall Market }\end{array} & \begin{array}{l}\text { Coefficient on } \\ \text { Dummy for event } \\ \text { period }\end{array} & \begin{array}{l}\text { F Value for } \\ \text { Regression } \\ \text { significance }\end{array} & \text { Adjusted R2 } \\ -0.1247 & 0.9304 & \mathbf{0 . 5 5 9 0} & 74.13 & 0.3497 \\ (0.0596)^{* *} & (0.0802)^{* * *} & (0.2059)^{* * *} & & \end{array}$

